\title{
A Correlative Study of Fine Needle Aspiration Cytology with Histopathology of Female Breast Lesions
}

\author{
Phirthangmoi Fimate ${ }^{1}$ \\ ${ }^{1}$ Department of Pathology, Jawaharlal Nehru Institute of Medical Sciences (JNIMS), Imphal, Manipur, India.
}

ABSTRACT

\section{BACKGROUND}

Breast lesions remain a major public health problem worldwide. Fine needle aspiration cytology (FNAC) has become one of the first-line investigations for the diagnosis of breast lumps. Although one of the major goals of FNAC is to differentiate benign from malignant lesions, in certain cases, this may not possible due to a lack of uniformity with regards to the reporting terminology used in breast cytology by pathologists worldwide, resulting in poor communication of results among health-care providers. The present study aims to evaluate the role and diagnostic accuracy of FNAC in the evaluation of breast lesions using the National Cancer Institute (NCI) recommended terminology by correlating with histopathological examination (HPE) results.

\section{METHODS}

In this retrospective study conducted over a period of two years, a total of 382 female patients with breast lesions underwent FNAC and was categorized according to the NCI guidelines. Of these, 156 cases had histopathological follow-up and their FNAC diagnoses were compared. The sensitivity, specificity, positive predictive value (PPV), and negative predictive value (NPV) along with 95\% confidence interval $(95 \% \mathrm{CI})$ and accuracy of FNAC were calculated.

\section{RESULTS}

Among the 156 cases, none were unsatisfactory (C1); 105 (67.1\%) were benign (C2); 7 (4.4\%) were atypical but probably benign (C3); 2 (1.1\%) were suspicious favouring malignancy (C4); 43 (27.4\%) were malignant (C5). Cyto-histopathological correlation was carried out. Of categories C2 and C3 (total of 112 cases), 109 were confirmed as benign (true negative) and the remaining 3 cases turned out to be malignant (false negative). Of categories C4 and C5 (total of 45 cases), all cases were confirmed as malignant (true positive) and none were benign (false positive). The present study showed a sensitivity, specificity, PPV, NPV and accuracy of $93.62 \%$ (95\% CI, 82.46\%-98.66\%), 100\% (95\% CI, 96.67\%-100\%), 100\% (95\% CI, 92.5\%99.6\%), 97.32\% (95\% CI, 92.4\%-99.09\%) and 98.08\% respectively.

\section{CONCLUSIONS}

Our study concluded that FNAC is a rapid and effective method, and reporting of smears using NCI guidelines highly correlated with the histopathological diagnosis.

\section{KEY WORDS}

Breast Lesions, Cytodiagnosis, Histopathologic Diagnosis, Fine-Needle Aspiration Cytology, Histopathological Examination, National Cancer Institute
Corresponding Author: Dr. Phirthangmoi Fimate, Ebenezer Villa, Near Shija Hospital, Langol, Imphal West-795004, Manipur, India.

E-mail: drmoite@gmail.com

DOI: $10.14260 / \mathrm{jemds} / 2020 / 246$

Financial or Other Competing Interests: None.

How to Cite This Article:

Fimate P. A correlative study of fine needle aspiration cytology with histopathology of female breast lesions. J. Evolution Med. Dent. Sci. 2020;9(14):1135-1139, DOI: $10.14260 /$ jemds/2020/246

Submission 30-01-2020,

Peer Review 15-03-2020,

Acceptance 21-03-2020,

Published 06-04-2020.

\section{(9)}




\section{BACKGROUND}

Lesions of the breast constitute a major public health problem worldwide, both in developed as well as in developing countries.1-3 A palpable breast lump, whether benign or malignant, is a cause of great anxiety to the patient. ${ }^{4}$ Thus, the need arises to distinguish benign from malignant lesions, prior to definitive treatment. Fine needle aspiration cytology (FNAC) is a simple procedure that involves passing a fine (22-24 G) needle fitted to an air-tight syringe, through the skin, to sample fluid or tissue from a solid or cystic mass. The extracted material is skilfully smeared onto a glass slide and is air-dried or fixed, stained rapidly, studied and diagnosis rendered promptly. ${ }^{5}$

Investigations like ultrasonography and mammography are used as an adjunct to FNAC, with biopsy as the standard procedure in the diagnosis of breast lesions. The triple test approach, which comprises clinical breast examination, radiological imaging (sonography and mammography), and pathological assessment with FNAC however remains an excellent tool in the initial assessment of palpable breast lumps as well as for screening asymptomatic patients. ${ }^{1,6,7}$ But each of these techniques have their own advantages and limitations. $6,8,9$

Histopathologic studies still remain the gold standard or reference point for establishing the diagnostic accuracy of cytological smears. However, surgical biopsy (either core needle biopsy [CNB] or excision) results in a large burden of surgery with major preparations, high cost (as compared to FNAC), hospital reservations, medico-legal complications, technological complexities and a large staff, long tissue processing time, cumbersome, and time consuming results, complications, interpretations, ${ }^{1,9}$ patient discomfort such as pain, infection, bleeding and haematoma, and the risk of seeding of the tumour along the needle track in case of core biopsies. ${ }^{6}$ Hence, FNAC helps to determine when the surgical approach is warranted.

With the obvious advantages of ease, simplicity, rapidity, inexpensive and virtually painless procedure and with a high percentage of sensitivity, specificity, accuracy and virtually no complications, FNAC has become a standard tool and one of the first-line investigations for the diagnosis of breast lumps. ${ }^{1-6,8,10,11}$ Moreover, FNAC is a relatively safe procedure in certain circumstances like very small lesions, superficial lesions, or lesions very close to the chest wall as compared to biopsies. In addition, FNAC maintains tactile sensitivity, allows multi-directional passes allowing a broader sampling of lesion, and immediate reporting whenever necessary. ${ }^{1}$

FNAC is not only useful in diagnosis and further planning of treatment without need for biopsy, but also helpful in prognostication of the tumour factors such as nuclear grading, mitotic index, hormone receptor status and DNA contents. ${ }^{2}$ Especially in developing countries and countries with limited resources, majority of breast malignancies are advanced $^{7}$ and an unequivocal pre-operative diagnosis of malignancy is frequently required by surgeons in order to justify a more intense medical evaluation for metastatic disease. In such settings, FNAC serves as a cost-effective alternative to open surgical biopsy. However, successful
FNAC demands high specimen quality and experience on part of both the aspirator and the cytopathologist. ${ }^{9}$

Accurate pathological diagnosis is crucial for further treatment and estimation of an outcome. One of the major goals of FNAC is to differentiate benign from malignant lesions. However, in certain instances, differentiation of benign from malignant lesion is not possible due to significant overlap on smears and also when there is a paucity of cells. To address these cytomorphologic uncertainties and to bring a higher degree of uniformity to the reporting terminology so as to limit false positive or false negative results, the National Cancer Institute (NCI) proposed five diagnostic categories, based on the National Health Services Breast Screening Programme (NHSBSP) of Britain proposed in 1996 namely, C1, C2, C3, C4 and C5.1,4

In the present study, we aim to evaluate the role and diagnostic accuracy of FNAC in the evaluation of breast lesions using the NCI recommended terminology by correlating with histopathological results.

\section{METHODS}

Ethical clearance was applied for and obtained from the Institutional Ethics Committee before the commencement of the present study. A retrospective study was conducted over a period of two years, i.e., between the period of January 2011 to December 2012. The data of all patients presenting with breast lump who underwent FNAC in the Cytology division of Pathology Department, JNIMS, Manipur, during this period were retrieved and reviewed. Only the female breast cases were further analysed. Details concerning age, laterality and site of the breast lesions were recorded. Available cytopathologic reports and slides were retrieved and the cytomorphological features of all the lesions were further studied.

Informed consent had been taken. All patients had been made to lie down on the examination bed and all breast lump aspirates had been performed using 22-24-gauge needle and $10 \mathrm{~mL}$ syringe by the cytopathologist under aseptic precautions. The aspirated material was then smeared onto a minimum of 5 clean, dry and grease-free slides. One slide was rapidly stained with Leishman stain for a minute and examined for sample adequacy. Three slides were air dried and stained with May-Grunwald-Giemsa stain. One slide was wet-fixed in 95\% ethyl alcohol and subsequently stained with Papanicolaou stain. The stained smears were then classified into five major diagnostic categories after screening and interpretation by applying the probabilistic approach ${ }^{4}$ : These were C1, Non diagnostic/unsatisfactory/unremarkable; C2, Benign; C3, Atypical; C4, Suspicious for malignancy; and C5, Malignant.

Records of subsequent excisional biopsies or mastectomies were also retrieved from the Histopathology division of Pathology Department. Specimens had been fixed in $10 \%$ formalin solution, routinely processed, sectioned and stained with haematoxylin and eosin staining methods for microscopic examination. The histopathologic examination (HPE) reports and slides were retrieved and reviewed. Comparison was made with the corresponding cytopathology 
reports and codes for correlation. Patients with C2 and C3 diagnoses by FNAC and confirmed as benign on HPE were taken as true negative, while those confirmed as malignant on HPE were considered as false negative. Patients with $\mathrm{C} 4$ and C5 diagnoses by FNAC but confirmed as benign on HPE were considered as false positive, while those confirmed as malignant were considered true positive.

\section{Statistical Analysis}

All the statistical analysis was performed using Statistical Package for Social Sciences Statistics (SPSS) version 20. The sensitivity, specificity, positive predictive value (PPV), and negative predictive value (NPV) along with 95\% confidence interval $(95 \% \mathrm{CI})$, accuracy, false positive rate, and false negative rate of FNAC for diagnosing malignant breast lesions were calculated. Qualitative data are summarized using frequency and percentage.

\section{RESULTS}

There was a total of 382 cases of female breast FNAC's during the period of January 2011 to December 2012. Satisfactory aspirates were obtained in all of the cases. The age at presentation ranged from 14 to 75 years with a mean age of 34 years with SD of 11.8 years. Benign lesions were more common in 21-30 years and malignant lesions in $41-50$ years (Table 1). All of the female patients presented with a unilateral breast lump. The right breast $(213,55.8 \%)$ and the upper outer quadrant $(263,68.8 \%)$ were most commonly involved. (Table 2). Among the 382 female breast FNAC cases, there were no category C1 cases (all satisfactory smears), C2 consisted of 290 (75.8\%), C3 consisted of 22 (5.8\%), C4 consisted of $4(1 \%)$, and C5 consisted of $66(17.3 \%)$ cases. Out of 290 cases of category C2, fibroadenoma (42.1\%, 161/382) was most common lesion as shown in Table 1.

Of these 382 FNAC cases, histopathological examination (HPE) report was documented in 156 cases with a biopsy rate of $40.8 \%$ of which, none were C1, $105(67.1 \%)$ were C2, 7 (4.4\%) were C3, $2(1.1 \%)$ were C4, and $43(27.4 \%)$ were C5 as in Table 3. The comparison of these 156 cases of FNAC diagnoses with corresponding HPE diagnoses was done. On HPE, 99\% (104/105) cases of C2 were confirmed as benign and the remaining 1 case turned out to be malignant (infiltrating lobular carcinoma, ILC). In C3, benign lesions were confirmed in $71.4 \%(5 / 7)$ and the remaining two cases (28.6\%) were diagnosed to be malignant. In both C4 and C5, all the cases were correctly cytodiagnosed as malignant with a cyto-histological concordance of $100 \%$ (45/45). The most common malignant lesion noted in C5 on HPE was invasive ductal carcinoma-not otherwise specified (IDC-NOS, 43/47, 91.5\%). (Table 3)

The present study showed a sensitivity of $93.62 \%(95 \%$ CI, 82.46\%-98.66\%), specificity of $100 \%$ (95\% CI, 96.67\%$100 \%$ ), PPV of $100 \%$ (95\% CI, $92.5 \%-99.6 \%$ ), NPV of $97.32 \%$ (95\% CI, 92.4\%-99.09\%), and accuracy of $98.08 \%$ for FNAC in the diagnosis of malignant lesions. The false positive and false negative rate was $0 \%$ and $6.4 \%$, respectively.

\begin{tabular}{|c|c|c|c|c|c|c|c|c|c|c|c|c|}
\hline & & & & C2 & & & & C3 & C4 & C5 & & \\
\hline Age & 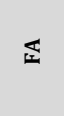 & $\frac{n}{\frac{n}{5}}$ & $\stackrel{\text { ப் }}{\dot{\varepsilon}}$ & త్రి & तु่ & 莺 & 을 & $\frac{\bar{d}}{\frac{\pi}{4}}$ & $\begin{array}{l}\frac{n}{0} \\
\frac{0}{\tilde{u}} \\
\bar{n} \\
\tilde{\omega}\end{array}$ & 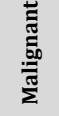 & Total & $\%$ \\
\hline $11-20$ & 46 & 2 & 2 & 0 & 0 & 1 & 1 & 0 & 0 & 0 & 52 & 13.6 \\
\hline $21-30$ & 73 & 20 & 7 & 14 & 1 & 3 & 1 & 5 & 0 & 2 & 126 & 33.0 \\
\hline $31-40$ & 29 & 17 & 8 & 14 & 1 & 0 & 0 & 12 & 2 & 20 & 103 & 27.0 \\
\hline $41-50$ & 11 & 8 & 5 & 21 & 0 & 0 & 0 & 4 & 1 & 22 & 72 & 18.8 \\
\hline $51-60$ & 2 & 0 & 1 & 2 & 0 & 0 & 0 & 1 & 1 & 17 & 24 & 6.3 \\
\hline $61-70$ & 0 & 0 & 0 & 0 & 0 & 0 & 0 & 0 & 0 & 4 & 4 & 1.0 \\
\hline $71-80$ & 0 & 0 & 0 & 0 & 0 & 0 & 0 & 0 & 0 & 1 & 1 & 0.3 \\
\hline Total & 161 & 47 & 23 & 51 & 2 & 4 & 2 & 22 & 4 & 66 & 382 & 100.0 \\
\hline$\%$ & 42.1 & 12.3 & 6.0 & 13.4 & 0.5 & 1.0 & 0.5 & 5.8 & 1.0 & 17.3 & 100.0 & \\
\hline
\end{tabular}

\begin{tabular}{|ccccccc|}
\hline \multicolumn{7}{c|}{ Quadrant } \\
Laterality & UO & UI & LO & LI & Total & $\mathbf{\%}$ \\
Right & $152(39.8 \%)$ & $34(8.9 \%)$ & $18(4.7 \%)$ & $9(2.4 \%)$ & 213 & $55.8 \%$ \\
Left & $111(29.1 \%)$ & $33(8.6 \%)$ & $16(4.2 \%)$ & $9(2.4 \%)$ & 169 & $44.2 \%$ \\
Total & $\mathbf{2 6 3}$ & $\mathbf{6 7}$ & $\mathbf{3 4}$ & $\mathbf{1 8}$ & $\mathbf{3 8 2}$ & $\mathbf{1 0 0} \%$ \\
$\mathbf{\%}$ & $\mathbf{6 8 . 8 \%}$ & $\mathbf{1 7 . 5 \%}$ & $\mathbf{8 . 9 \%}$ & $\mathbf{4 . 7 \%}$ \\
\hline UO-Upper outer, UI-Upper inner, LO-Lower outer, LI-Lower inner \\
\hline \multicolumn{7}{|c|}{ Table 2. Laterality and Quadrant } \\
\hline
\end{tabular}

\begin{tabular}{|c|c|c|c|c|c|c|c|c|c|c|c|c|}
\hline \multirow[b]{2}{*}{ C } & \multirow[b]{2}{*}{ 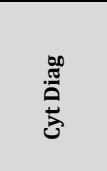 } & \multicolumn{11}{|c|}{ HPE } \\
\hline & & 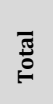 & $\stackrel{n}{\gtrless}$ & $\mathbb{E}$ & $\frac{n}{\sqrt[n]{5}}$ & త్ & $\begin{array}{l}\text { 을 } \\
\text { 롱 }\end{array}$ & 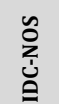 & 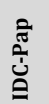 & $\stackrel{\text { U }}{=}$ & $\begin{array}{l}\overleftarrow{J} \\
\text { 욀 }\end{array}$ & $\begin{array}{l}\overleftarrow{J} \\
\text { } \\
\Sigma\end{array}$ \\
\hline \multirow{10}{*}{$\begin{array}{l}2 \\
3 \\
4 \\
5\end{array}$} & FA & 74 & 0 & 73 & 0 & 0 & 0 & 0 & 0 & 1 & 0 & 0 \\
\hline & Abs. & 5 & 5 & 0 & 0 & 0 & 0 & 0 & 0 & 0 & 0 & 0 \\
\hline & Granulo & 1 & 0 & 0 & 0 & 0 & 1 & 0 & 0 & 0 & 0 & 0 \\
\hline & Fasis & 2 & 0 & 0 & 2 & 0 & 0 & 0 & 0 & 0 & 0 & 0 \\
\hline & FCD & 23 & 0 & 0 & 0 & 23 & 0 & 0 & 0 & 0 & 0 & 0 \\
\hline & Atypical & 7 & 0 & 2 & 0 & 3 & 0 & 1 & 1 & 0 & 0 & 0 \\
\hline & Suspicious & 1 & 0 & 0 & 0 & 0 & 0 & 1 & 0 & 0 & 0 & 0 \\
\hline & Malignant & 43 & 0 & 0 & 0 & 0 & 0 & 41 & 0 & 0 & 1 & 1 \\
\hline & Total & 156 & 5 & 75 & 2 & 26 & 1 & 43 & 1 & 1 & 1 & 1 \\
\hline & $\%$ & & 3.2 & 48.2 & 1.3 & 16.7 & 0.6 & 27.6 & 0.6 & 0.6 & 0.6 & 0.6 \\
\hline
\end{tabular}

CytDiag-Cytologic Diagnosis, HPE-Histopathologic Examination, FA-Fibroadenoma, Abs-Abscess, Fasis-Fibroadenosis, FCD-Fibrocystic disease, Granulo-Granulomatous mastitis, IDC-Infiltrating duct carcinoma, NOS-Not otherwise specified, Pap-

Papillary, ILC-Infiltrating lobular carcinoma, Med Ca-Medullary carcinoma, Muc CaMucinous carcinoma.

Table 3. Comparison of Cytology with Histopathology Reports

\begin{tabular}{|c|c|c|c|c|c|c|c|}
\hline$\underset{己}{\vec{Z}}$ & 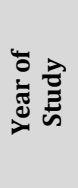 & 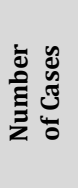 & 总 & 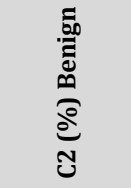 & 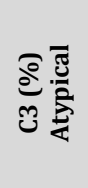 & 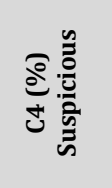 & ○ \\
\hline $\begin{array}{l}\text { Ukah and } \\
\text { Oluwasola }^{12}\end{array}$ & 2005 & 1401 & $38(2.7)$ & $803(57.3)$ & $6(0.4)$ & $107(7.6)$ & 447 (31.9) \\
\hline Challa et al ${ }^{13}$ & 2010 & 812 & $8(0.9)$ & 314 (38.6) & $27(3.3)$ & $12(1.4)$ & $451(55.5)$ \\
\hline Sankaye et $\mathrm{al}^{2}$ & 2012 & 225 & $13(5.8)$ & $131(58.2)$ & $8(3.6)$ & $8(3.5)$ & $65(28.9)$ \\
\hline $\begin{array}{l}\text { Chokshi and } \\
\text { Mehta }^{14}\end{array}$ & 2012 & 407 & $28(6.9)$ & $293(71.9)$ & $8(2)$ & $8(2)$ & $70(17.2)$ \\
\hline Singh et $\mathrm{al}^{15}$ & 2014 & 100 & $5(5)$ & $51(51)$ & $2(2)$ & $3(3)$ & $39(39)$ \\
\hline $\begin{array}{l}\text { Arul and } \\
\text { Masilamani }{ }^{1}\end{array}$ & 2015 & 523 & $14(2.7)$ & $352(67.3)$ & $27(5.2)$ & $41(7.8)$ & $89(17)$ \\
\hline $\begin{array}{l}\text { Madubogwu } \\
\text { et } \mathrm{al}^{10}\end{array}$ & 2017 & 110 & 17 & 46 & 5 & 4 & 38 \\
\hline Veena et al ${ }^{16}$ & 2017 & 178 & $4(2.2)$ & $134(75.28)$ & $14(7.8)$ & $6(3.3)$ & $20(11.2)$ \\
\hline Present study & 2019 & 382 & 0 & $290(75.8)$ & $22(5.8)$ & $4(1.0)$ & $66(17.3)$ \\
\hline \multicolumn{8}{|c|}{$\begin{array}{l}\text { Table 4. Comparison of the Distribution of Various National Cancer } \\
\text { nstitute Guidelines Comparison of Present Study with Published Studies }\end{array}$} \\
\hline \multicolumn{2}{|l|}{ Study } & $\begin{array}{l}\text { Year of } \\
\text { Study }\end{array}$ & \multicolumn{2}{|c|}{$\begin{array}{l}\text { No. of Benign } \\
\text { Cases (\%) }\end{array}$} & \multicolumn{3}{|c|}{$\begin{array}{l}\text { No. of Malignant } \\
\text { Cases }(\%)\end{array}$ Total } \\
\hline \multirow{2}{*}{\multicolumn{2}{|c|}{$\begin{array}{l}\text { Ukah and Oluwasola }{ }^{12} \\
\text { Nguansangiam et } \text { al }^{17}\end{array}$}} & 2005 & & $126(50.4)$ & & $124(49.6)$ & 250 \\
\hline & & 2006 & & $102(56)$ & & $80(44)$ & 182 \\
\hline \multicolumn{2}{|c|}{ Sankaye and Dongre ${ }^{2}$} & 2012 & & $31(40.8)$ & & $45(59.2)$ & 76 \\
\hline \multicolumn{2}{|c|}{ Yusuf and Atanda ${ }^{18}$} & 2012 & & $117(58.5)$ & & $83(41.5)$ & 200 \\
\hline \multirow{2}{*}{\multicolumn{2}{|c|}{ Arul and Masilamani ${ }^{1}$}} & 2015 & & $198(69.2)$ & & $88(30.8)$ & 286 \\
\hline & & 2015 & & 398 (91.3) & & $38(8.7)$ & 436 \\
\hline \multicolumn{2}{|c|}{ Madubogwu et al ${ }^{10}$} & 2017 & & $58(52.7)$ & & $52(47.3)$ & 110 \\
\hline \multicolumn{2}{|c|}{ Veena et al 16} & 2017 & & $112(78.9)$ & & $30(21.1)$ & 142 \\
\hline Present stu & ddy & 2019 & & $109(70)$ & & $47(30)$ & 156 \\
\hline \multicolumn{8}{|c|}{ Table 5. Comparison of Histopathological Cases } \\
\hline
\end{tabular}




\begin{tabular}{|c|c|c|c|c|c|c|}
\hline$\frac{2}{\tilde{E}}$ & 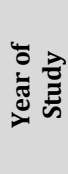 & 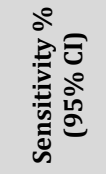 & 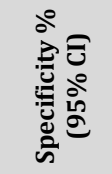 & 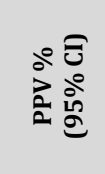 & 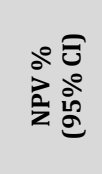 & 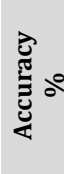 \\
\hline $\begin{array}{l}\text { Sankaye and } \\
\text { Dongre }^{2}\end{array}$ & 2012 & 88.37 & 96.42 & 97.43 & 84.37 & 91.54 \\
\hline $\begin{array}{c}\text { Arul and } \\
\text { Masilamani }^{1}\end{array}$ & 2015 & $\begin{array}{c}93.1 \\
(88.2 \%- \\
95 \%)\end{array}$ & $\begin{array}{c}99 \\
(96.8 \%- \\
99.8 \%)\end{array}$ & $\begin{array}{c}97.6 \\
(92.5 \%- \\
99.6 \%)\end{array}$ & $\begin{array}{c}97 \\
(94.9 \%- \\
97.8 \%)\end{array}$ & 97.20 \\
\hline Madubogwu et $\mathrm{al}^{10}$ & 2017 & 90 & 95.50 & 94.70 & 91.30 & 92.90 \\
\hline Veena et al ${ }^{16}$ & 2017 & 99.23 & 90.17 & 92.19 & 99.01 & \\
\hline Present Study & 2019 & $\begin{array}{c}93.62 \\
(82.46 \%- \\
98.66 \%) \\
\end{array}$ & $\begin{array}{c}100 \\
(96.67 \%- \\
100 \%) \\
\end{array}$ & $\begin{array}{c}100 \\
(92.5 \%- \\
99.6 \%) \\
\end{array}$ & $\begin{array}{c}97.32 \\
(92.4 \%- \\
99.09 \%) \\
\end{array}$ & 98.08 \\
\hline \multicolumn{7}{|c|}{$\begin{array}{c}\text { Table 6. Comparison of Statistical Analyses of FNAC } \\
\text { of the Present Study with Published Studies }\end{array}$} \\
\hline
\end{tabular}

\section{DISCUSSION}

In the present study, benign breast lesions were more common in 21-30 years, which was similar to studies by Veena et al. ${ }^{16}$ Malignant breast lesions were most common in 41-50 years, which were comparable to studies by Arul et al. ${ }^{1}$ The present study shows that benign lesions are common in the younger age group and malignancy rates increase with increasing age of patients. The right breast $(213,55.8 \%)$ was found to be more commonly involved in the present study, which was in contrast to some published findings ${ }^{1,2}$; however, the upper outer quadrant $(263,68.8 \%)$ was the most common location which is similar to findings by the same researchers. ${ }^{1,2}$

The distribution of the FNAC diagnoses of breast lesions using NCI guidelines (1996) in our institution as compared with published studies is shown in Table 4. Categories C2 to C5 of our study were comparable to frequencies found in most published studies. In the present study, there were no C1 categories, since rapid stain was conducted for all cases to determine specimen adequacy; Categories C2 and C5 are straightforward and has been associated with a high degree of diagnostic accuracy as was observed in the present study (99\% and 100\% respectively). However, the interpretation of C3 and C4 are difficult and confusing because they do not have strict criteria for diagnosis. Some researchers have suggested clubbing of $\mathrm{C} 3$ and $\mathrm{C} 4$ as a single term called equivocal/suspicious category as they believe that a Core needle biopsy (CNB) or surgical biopsy should be done for this combined category, as the incidence of malignancy is significant in both subgroups. In the present study, benign and malignant outcome of C3 was $71.4 \%$ and $28.6 \%$, while malignant outcome of $\mathrm{C} 4$ was $100 \%$, which is comparable to large-scale studies with histopathological correlation. Since the current study showed $71.4 \%$ benign lesions with C3 and $100 \%$ malignancy with $\mathrm{C} 4$, we feel that it is still useful to maintain the categories C3 and C4 separately.

On HPE of the 156 cases, benign cases $(69.9 \%, 109 / 156)$ were more common as compared to malignant cases $(30.1 \%$, 47/156). This finding was similar to various studies $1,16,18,17$ [Table 4].The most common benign and malignant breast lesions on HPE was fibroadenoma and IDC-NOS respectively. These findings were comparable to various published studies. $1,2,7,8,10,16,18$ One case of ILC was under-diagnosed as fibroadenoma in $\mathrm{C} 2$, one case of IDC-NOS and papillary misdiagnosed as $\mathrm{C} 3$ on FNAC, contributing to false negative results. Factors contributing to false negative results may include the small size of the lesion, hypocellularity, and inadequate sampling during aspiration, histological tumour types such as low nuclear grade in ILC, and well-differentiated intracystic papillary carcinoma. All cases from C4 and C5 was diagnosed as malignant on HPE. These results were considered as true positive. Both false negative and false positive diagnoses can be reduced by good sampling technique, proper tumour localization, triple assessment, and more importantly availing expert second opinions for doubtful cases.

The present study showed a sensitivity of $93.62 \%(95 \%$ CI, $82.46 \%-98.66 \%$ ), specificity of $100 \%$ (95\% CI, 96.67\%$100 \%$ ), PPV of $100 \%$ (95\% CI, 92.5\%-99.6\%), NPV of $97.32 \%$ (95\% CI, 92.4\%-99.09\%), and accuracy of $98.08 \%$ for FNAC in the diagnosis of malignant lesions, comparable to other published studies as in Table 6.

\section{CONCLUSIONS}

Fine-needle aspiration cytology is a rapid and effective method for the primary categorization of palpable breast lumps into benign, malignant, atypical, suspicious, and unsatisfactory categories. Benign breast lesions are common than malignant lesions, fibroadenoma is the most common benign breast lesion, whereas IDC accounts for the highest number of malignant lesions. Histological correlation indicated FNAC to be a good diagnostic tool.

\section{REFERENCES}

[1] Arul P, Masilamani S. Application of National Cancer Institute recommended terminology in breast cytology. J Can Res Ther 2017;13(1):91-6.

[2] Sankaye SB, Dongre SD. Cytological study of palpable breast lumps presenting in an Indian rural setup. Indian J Med Paediatr Oncol 2014;35(2):159-64.

[3] Chaudhury SMSA, Alam MK, Haque MS. The role of FNAC in diagnosis of breast disease at different ages - 208 cases. Journal of Bangladesh College of Physicians and Surgeons 2012;30(3):137-40.

[4] Pandya AN, Shah NP. Breast fine needle aspiration cytology reporting: a study of application of probabilistic approach. Indian Medical Gazette 2013: p. 54-9.

[5] Orell SR, Sterrett GF, Whitaker D, et al. Breast. Fine needle aspiration cytology. $4^{\text {th }}$ edn. Churchill Livingstone 2005: p. 165-217.

[6] Daramola AO, Odubanjo MO, Obiajulu FJ, et al. Correlation between fine-needle aspiration cytology and histology for palpable breast masses in a Nigerian Tertiary Health Institution. International Journal of Breast Cancer 2015;2015:742573.

[7] Rupom TU, Choudhury T, Banu SG. Study of fine needle aspiration cytology of breast lump: correlation of cytologically malignant cases with their histological findings. BSMMU J 2011;4(2):60-4.

[8] Almobarak AO, Elhassan TM, Elhoweris $\mathrm{MH}$, et al. Cytomorphologic patterns of breast lesions in Sudanese 
patients: lessons learned from fine needle aspiration cytology. Asian Pac J Cancer Prev 2014;15(8):3411-3.

[9] Kumar CA, Kumar PA, Tarannum K, et al. Study of breast lesions in a tertiary care centre: a retrospective study. Med Phoenix: An Official Journal of NMC, Birgunj, Nepal 2017;2(1):48-51.

[10] Madubogwu CI, Ukah CO, Anyanwu Snc, et al. Subclassification of breast masses by fine needle aspiration cytology. Eur J Breast Health 2017;13(4):194-9.

[11] Tiwari M. Role of fine needle aspiration cytology in diagnosis of breast lumps. Kathmandu University Medical Journal 2007;5(2):215-7.

[12] Ukah CO, Oluwasola OA. The clinical effectiveness of fine needle aspiration biopsy in patients with palpable breast lesions seen at the University College Hospital, Ibadan, Nigeria: a 10-year retrospective study. J Cytol 2011;28(3):111-3.

[13] Challa VR, Guru BGY, Rangappa P, et al. Cytological and pathological correlation of FNAC in assessing breast lumps and axillary lymph node swellings in a public sector hospital in India. Patholog Res Int 2013;2013:695024.

[14] Chokshi MH, Mehta NP. Cytological study of palpable breast lumps (407 cases) with their histological correlation. Int J Med Sci Public Health 2014;3(2):181-5.

[15] Singh P, Chaudhry M, Nauhria S, et al. Cytomorphological patterns of breast lesions diagnosed on fine-needle aspiration cytology in a tertiary care hospital. Int J Med Sci Public Health 2015;4(5):674-9.

[16] Veena KL, Vani R, Jijiya BP, et al. Evaluation of breast lumps by fine needle aspiration cytology in correlation with histopathology. J Cont Med A Dent 2017;5(1):63-7.

[17] Nguansangiam S, Jesdapatarakul S, Tangjitgamol S. Accuracy of fine needle aspiration cytology from breast masses in Thailand. Asian Pac J Cancer Prev 2009;10(4):623-6.

[18] Yusuf I, Atanda AT. Validity of fine needle aspiration cytology of the palpable breast lesions: a teaching hospital experience. Niger J Basic Clin Sci 2014;11(1):36-40. 